\title{
Exercise Influence on Hippocampal Function: Possible Involvement of Orexin-A
}

\author{
Sergio Chieffi ${ }^{1 \dagger}$, Giovanni Messina ${ }^{1,2+*}$, Ines Villano ${ }^{1}$, Antonietta Messina ${ }^{1}$, \\ Maria Esposito ${ }^{3}$, Vincenzo Monda ${ }^{1}$, Anna Valenzano ${ }^{2}$, Fiorenzo Moscatelli ${ }^{2}$, \\ Teresa Esposito ${ }^{1}$, Marco Carotenuto ${ }^{3}$, Andrea Viggiano ${ }^{4}$, Giuseppe Cibelli ${ }^{1}$ and \\ Marcellino Monda ${ }^{2}$
}

${ }^{1}$ Section of Human Physiology and Unit of Dietetic and Sport Medicine, Department of Experimental Medicine, Second University of Naples, Naples, Italy, ${ }^{2}$ Department of Clinical and Experimental Medicine, University of Foggia, Foggia, Italy, ${ }^{3}$ Department of Mental Health, Physical and Preventive Medicine, Clinic of Child and Adolescent Neuropsychiatry, Center for Childhood Headache, Second University of Naples, Naples, Italy, ${ }^{4}$ Department of Medicine and Surgery, University of Salerno, Salerno, Italy

OPEN ACCESS

Edited by:

Gary Iwamoto,

University of Illinois at

Urbana-Champaign, USA

Reviewed by:

Chelsea M. Stillman,

University of Pittsburgh School of

Medicine, USA

Agnieszka Z. Burzynska,

Colorado State University, USA

*Correspondence:

Giovanni Messina

gianni.messina@unina2.it

${ }^{\dagger}$ These authors have contributed equally to this work.

Specialty section: This article was submitted to

Exercise Physiology,

a section of the journal

Frontiers in Physiology

Received: 05 July 2016 Accepted: 30 January 2017 Published: 14 February 2017

Citation:

Chieffi S, Messina G, Villano I, Messina A, Esposito M, Monda V, Valenzano A, Moscatelli F, Esposito T, Carotenuto M, Viggiano A, Cibelli G and Monda M (2017) Exercise Influence on Hippocampal Function: Possible Involvement of Orexin-A.

Front. Physiol. 8:85

doi: 10.3389/fphys.2017.00085
In the present article, we provide a brief review of current knowledge regarding the effects induced by physical exercise on hippocampus. Research involving animals and humans supports the view that physical exercise, enhancing hippocampal neurogenesis and function, improves cognition, and regulates mood. These beneficial effects depend on the contribute of more factors including the enhancement of vascularization and upregulation of growth factors. Among these, the BDNF seems to play a significant role. Another putative factor that might contribute to beneficial effects of exercise is the orexin-A. In support of this hypothesis there are the following observations: (1) orexin-A enhances hippocampal neurogenesis and function and (2) the levels of orexin-A increase with physical exercise. The beneficial effects of exercise may represent an important resource to hinder the cognitive decline associated with the aging-related hippocampal deterioration and ameliorate depressive symptoms.

\section{Keywords: hippocampus, plasticity, neurogenesis, exercise, orexins, cognition, mood, depression}

\section{INTRODUCTION}

For many years, researchers believed that neurogenesis, i.e., the production of new neurons through the division of stem cells within the brain, takes place only during embryonic development and not when the brain is fully developed. However, in recent decades, experimental evidence has shown that neurogenesis occurs also in the adult brain in two particular regions: the olfactory bulb, involved in the perception of odors, and the hippocampus, mainly involved in memory consolidation (Whitman and Greer, 2009; Kempermann et al., 2015). In the hippocampus, multipotent undifferentiated neural stem cells, located in the subgranular zone of the dentate gyrus, give rise to neural progenitor cells. These cells proliferate and migrate into the granule cell layer and differentiate into neurons, astroglia, or oligodendrocytes. The newborn neurons project into the CA3 region where they are integrated in functional circuits (Gage, 2000; Kempermann et al., 2004). A seminal study by Eriksson et al. (1998) provided direct evidence for adult neurogenesis in humans. These authors (Eriksson et al., 1998) obtained postmortem human brain tissue from adult patients who received, for diagnostic purposes, bromodeoxyuridine that labels DNA during 
the S phase. Eriksson et al. (1998) demonstrated that new neurons were generated from dividing progenitor cells in the dentate gyrus. Spalding et al. (2013) estimated that about 700 new neurons are added in each hippocampus per day.

\section{EXERCISE AND HIPPOCAMPUS: ANIMAL MODEL}

Hippocampal neurogenesis is favored by many factors, including environmental enrichment and voluntary exercise and associative learning (Kempermann et al., 1997, 1998; van Praag et al., 1999a,b, 2005). Regarding the enriched environment, it is a complex combination of social, cognitive, and physical stimulations. van Praag et al. (1999b) attempted to disentangle such components and observed that voluntary exercise doubled the number of surviving newborn cells in amounts similar to enrichment condition. Then, van Praag et al. (1999b) suggested that voluntary exercise was sufficient for enhanced neurogenesis in the adult mouse dentate gyrus. Interestingly, the effect of exercise on neurogenesis appears to be restricted to the hippocampus. This was demonstrated by Brown et al. (2003) who found that voluntary exercise selectively doubled the amount of new granule cells in the hippocampus, but it did not modify the number of adult-generated olfactory granule cells. Another effect of exercise is the increase of cerebral blood volume of the dentate gyrus in mice (Pereira et al., 2007). This increase was considered an in vivo correlate of neurogenesis since it correlated with postmortem measurements of neurogenesis (Pereira et al., 2007). Hippocampal neurogenesis diminishes with aging (Kuhn et al., 1996; Heine et al., 2004). However, van Praag et al. (2005) suggested that this decrease may be partially opposed by exercise. The Authors (van Praag et al., 2005) reported that in aged running mice voluntary exercise enhanced hippocampal neurogenesis and learning. Interestingly, the morphology of new neurons did not differ between young and aged runners, supporting the hypothesis that local hippocampal environment of the aged dentate gyrus is effective in sustaining neurogenesis (van Praag et al., 2005). Some researchers investigated the effects of hyppocampal lesion on behavioral performance. Clark et al. (2008) irradiated with gamma rays the region of mice hippocampus reducing neurogenesis by $50 \%$, whereas in non-irradiated animals running increased neurogenesis fourfold. Furthermore, irradiation selectively eliminated gains in water maze performance that depends on hippocampus. However, the decrease in neurogenesis and cognitive skills induced by irradiation could be mitigated by exercise (Ji et al., 2014). Rats who received whole-brain irradiation and, following irradiation, were forced to perform exercise showed a significant amelioration of the impaired neurogenesis and cognition (Ji et al., 2014).

The morphological and functional changes in hippocampus produced by exercise likely depend on the contribute of different factors, including the enhancement of vascularisation, the involvement of growth factors and the regulation of the expression in a variety of gene transcripts. Exercise upregulates expression of brain-derived neurotrophic factor
(BDNF), vascular endothelial growth factor (VEGF), and insulin-like growth factor-1 (IGF-1). Among these, the BDNF is considered to be the most important factor. A lot of studies suggest that the upregulation of BDNF play an significant role in hippocampal neurogenesis, synaptic plasticity and learning (Neeper et al., 1995; Cotman and Berchtold, 2002; Vaynman et al., 2004; Cotman et al., 2007).

\section{EXERCISE AND HIPPOCAMPUS: HUMANS}

An interesting and fruitful line of research in recent years has investigated the influence of exercise on cognitive functions in humans. Exercise may enhance cognitive functions both in young, e.g., improving verbal memory and performance in a map recognition (Grego et al., 2005; Pereira et al., 2007; Winter et al., 2007), and in older adults, e.g., enhancing efficiency of attentional (Kramer et al., 1999) and executive-control processes (Colcombe and Kramer, 2003). Pereira et al. (2007) found that in humans (21-45 years) exercise selectively increased the cerebral blood volume of the dentate gyrus. This increase correlated with improved verbal memory. Intriguingly, Griffin et al. (2011) found that acute and chronic exercise enhanced the performance of young ( $22 \pm 2$ years), sedentary (i.e., not involved in any regular physical training) men in the face-name matching task (associative memory) and not in the Stroop task (executive functions). Note that face-name matching task recruits the hippocampus and associated structures of the medial temporal lobe (Zeineh et al., 2003; Kirwan and Stark, 2004), whereas the Stroop word-color task the anterior cingulate cortex and other frontal regions (Leung et al., 2000). However, other researchers reported post-exercise improvements also in the performance of the Stroop word and color tests (Ferris et al., 2007).

As concerns cognitive functions in older adults, in general, healthy older adults with higher fitness levels have less cognitive decline (Yaffe et al., 2001; Barnes et al., 2003) and reduced risk for dementia and Alzheimer's disease (Podewils et al., 2005; Larson et al., 2006) than those with lower fitness levels. In older humans, imaging studies showed that exercise not only spared brain volume but also increased both gray and white matter volume in the prefrontal and temporal cortices, i.e., those same regions that are often reported to deteriorate with aging (Colcombe et al., 2006; Rosano et al., 2010) and be severely affected in Alzheimer's disease (Galeone et al., 2011; Chieffi et al., 2014a,b, 2015; Chieffi, 2016a). The integrity of these regions play central roles in successful everyday functioning. Prefrontal regions are associated with working memory and executive functions (Chieffi et al., 2008, 2012; Godefroy et al., 2008; Roca et al., 2010) and temporal lobes with long-term memory function (Jeneson and Squire, 2011; Lech and Suchan, 2013).

Exercise has also beneficial effects on the hippocampus, a brain region particularly sensitive to age-related decay. Hippocampus shrinks with age (Raz et al., 2005) and its atrophy predicts shorter time-to-progression from mild cognitive impairment to Alzheimer's dementia (Jack et al., 2010). Erickson et al. (2011) reported that older (55-80 years) individuals with higher levels of aerobic fitness were associated with greater volume of the hippocampus and displayed better spatial memory performance 
than individuals with lower fitness levels. One year aerobic exercise intervention was effective in increasing the size of the anterior hippocampus by $2 \%$ (Erickson et al., 2011), contrasting with the reported 1-2\% annual hippocampal volume shrinkage in older adults without dementia (Raz et al., 2005). Gains in hippocampal blood flow and memory performance were also observed in healthy sedentary adults (57-75 years) with shorter term exercise ( 3 months) by Chapman et al. (2013). More researches reported that exercise increased BDNF concentrations in the serum suggesting a key role for this neurotrophic factor in enhancing hippocampal volume and cognitive function (Ferris et al., 2007; Erickson et al., 2011; Griffin et al., 2011).

\section{EXERCISE, OREXIN, AND HIPPOCAMPUS}

Another factor that acting on the hippocampus might contribute to the beneficial effects of physical exercise on cognition is the orexin-A. The orexin-A/hypocretin-1 (OxA/Hcrt-1) and orexin-B/hypocretin-2 (OxB/Hcrt-2) are neuropeptides synthesized by a cluster of neurons in the lateral hypothalamus. Orexins selectively act on two G protein-coupled receptors: the orexin/hypocretin 1 receptor (Ox1R/HcrtR1), which has higher affinity to orexin-A, and the orexin/hypocretin 2 receptor (Ox2R/HcrtR2), which has equal affinity to both orexin-A and orexin-B (Sakurai et al., 1998; Scammell and Winrow, 2011). $\mathrm{Ox} 1 \mathrm{R}$ and $\mathrm{Ox} 2 \mathrm{R}$ are generally excitatory, being the common cellular response to their activation an increase of intracellular calcium (Gotter et al., 2012). Furthermore, orexin receptors may mediate both acute and long-lasting effects (Scammell and Winrow, 2011). Acute effects depend on several ionic mechanisms, such as the inhibition of potassium channels and the activation of a sodium/calcium exchanger; long-lasting effects by increasing the number of $N$-methyl- $D$-aspartate (NMDA) receptors in the cell membrane and making the neurons more responsive to the excitatory effects of glutamate for several hours (Scammell and Winrow, 2011). Ox1Rs are widely expressed throughout the brain, including hippocampal formation, dorsal raphe nucleus and locus coeruleus, while Ox2Rs are found mainly in the cerebral cortex, nucleus accumbens, and subthalamic and paraventricular thalamic nuclei (Trivedi et al., 1998; Marcus et al., 2001). Orexinergic neurons receive a variety of signals related to environmental, physiological, and emotional stimuli (Yoshida et al., 2006; Scammell and Winrow, 2011; Marra et al., 2013; Franco et al., 2014), and project broadly to the entire CNS. Orexinergic projections are involved in regulating wakefulness and arousal (Saper et al., 2005), motivation and emotions (Sakurai and Mieda, 2011; Thompson and Borgland, 2011; Boscia et al., 2015), and motor and autonomic functions (Nattie and Li, 2012; Messina et al., 2013, 2014b, 2015a,b; Messina A. et al., 2016). Orexinergic system may also induce structural changes in the hippocampus influencing hippocampal learning and memory processes. In support of this view Wayner et al. (2004) reported that local dentate gyrus perfusion with orexin-A enhanced long-term potentiation (LTP) in anesthetized rats, suggesting that orexins positively regulate hippocampal synaptic plasticity. Furthermore, the authors (Wayner et al., 2004) showed that this improvement was blocked when rats were pretreated with SB-334867, a specific Ox1R antagonist (Wayner et al., 2004). The effects of dentate gyrus-OX1Rs antagonization on LTP occurred also in freely moving rats (Akbari et al., 2011). Subsequently, Akbari et al. $(2007,2008)$ showed that blockade of Ox1Rs with SB-334867 in CA1 and in dentate gyrus regions impaired spatial memory in Morris water maze, suggesting endogenous orexin-A positively modulated the performance of learning tasks via Ox1Rs. Some studies examined the effects of orexin-A in rats in which the administration of Pentylenetetrazol (PTZ) induced seizures resulting in the hippocampal atrophy, learning and memory deficits and decrease of cerebrospinal fluid-level of orexin-A. Note that the levels of orexin-A in cerebrospinal fluid are decreased in patients after repetitive seizures (Rejdak et al., 2009). Zhao et al. (2014) observed that the intracerebroventricular (i.c.v.) injection of orexin-A in PTZ-kindled rats attenuated the impairment of spatial learning and memory. Furthermore, they (Zhao et al., 2014) showed that orexin-A enhanced neurogenesis in the dentate gyrus promoting neuronal proliferation and differentiation. Interestingly, in rats treated with orexin-A more than $50 \%$ of newborn cells differentiated into neurons, but only $\sim 30 \%$ of the newborn cells differentiated into neurons in the control group. This suggested that orexin-A not only stimulated cell proliferation but also promoted the differentiation of newborn cells (Zhao et al., 2014). Recently, Yang et al. (2013) showed that orexin-A is also implicated in social memory, i.e., the ability to distinguish and remember familiar from novel conspecifics. The authors (Yang et al., 2013) used orexin/ataxin-3-transgenic (AT) mice, in which orexin neurons degenerate by 3 months of age (Hara et al., 2001). Compared with their wild-type (WT) littermates, AT mice displayed deficits in long-term social memory. However, nasal administration of exogenous orexin-A restored social memory and enhanced synaptic plasticity in the hippocampus (Yang et al., 2013). Interestingly, Yang et al. (2013) found in the AT hippocampus an attenuation of LTP and a decrease of phosphorylated CREB (pCREB) levels. The authors (Yang et al., 2013) suggested that the alteration of these processes might underlie the long-term social memory deficit in AT mice. According previous studies showed that the formation of longterm memory in several hippocampus-dependent cognitive tasks involve CREB phosphorylation (Kogan et al., 2000; Nomoto et al., 2012) and neurotransmitters such as dopamine, serotonin, and acetylcholine, which enhance memory, induce CREB phosphorylation (Kogan et al., 2000; Shirayama and Chaki, 2006). Recently, it was reported that also orexin-B can improve memory processes. Palotai et al. (2014) showed that the i.c.v. administration of orexin-B in rats improved learning, memory consolidation and retrieval, in a dose-dependent manner. The action of orexin-B on memory functions was further supported by the observation that rats pretreated with the EMPA (N-ethyl-2-[(6-methoxy-pyridin-3-yl)-(toluene-2-sulphonyl)amino]-N-pyri-din-3-ylmethyl-acetamide), a selective Ox2R antagonist, reversed completely memory consolidation.

Physical exercise produces an increase of orexin-A level in cerebrospinal fluid of rats (Martins et al., 2004), dogs (Wu et al., 2002), and cats (Kiyashchenko et al., 2002). An increase of plasmatic orexin-A with exercise was reported in humans 
(Messina et al., 2014a; Messina G. et al., 2016). Messina et al. (2014a) collected blood samples from adult participants before (time $0 \mathrm{~min}$ ) and after (times 15 and $30 \mathrm{~min}$ ) a cycle ergo meter exercise at $75 \mathrm{~W}$ for $15 \mathrm{~min}$. Results showed that the post-exercise values of orexin-A were significantly higher compared to preexercise values. The source of peripheral orexin is still unclear. Tsunematsu and Yamanaka (2012) proposed that orexin A might be directly released from the pituitary into the blood stream, since orexin-immunoreactive fibers are present in the median eminence and pituitary (Date et al., 1999), or leaked from the cerebrospinal fluid. Furthermore, orexin-A may rapidly cross the blood-brain barrier from brain tissue to reach blood by the process of simple diffusion, being highly lipophilic (Kastin and Akerstrom, 1999). Peripheral tissues may represent another source of peripheral orexin. Orexin-immunoreactive cells are observed in the gastrointestinal tract and pancreas (Nakabayashi et al., 2003).

As a whole the experimental data we have reported allow to hypothesize that the increase of orexin-A levels with exercise may contribute to improve cognition, enhancing hippocampal plasticity, and function.

Experimental evidence also suggests that physical exercise, besides improving cognition, has beneficial effects on mood regulation. In support of an antidepressant effect of exercise there are exhaustive reviews (Blake et al., 2009; Bridle et al., 2012; Mura et al., 2014; Kvam et al., 2016). Interestingly, patients with depression showed smaller hippocampal volumes (Steffens et al., 2000; Sheline, 2003) and an increase in hippocampus volume following exercise was positively associated with depressive symptoms improvement (Krogh et al., 2014).

Orexin-A, as well as BDNF, might contribute to beneficial effects on mood regulation induced by exercise (Chieffi, 2016b). Wistar-Kyoto (WKY) rats represent a genetic animal model of depression. They have fewer (about 18\%) and smaller (about $15 \%$ ) orexin-A neurons in the hypothalamus compared to control Wistar rats (Allard et al., 2004). These observations were in line with the observation of Taheri et al. (2001) who reported a decrease of about $22 \%$ in hypothalamic prepro-orexin mRNA in WKY rats. Some studies have investigated the links between orexins, depression, and hippocampal neurogenesis. Arendt et al. (2013) found that mice displaying an increase of immobility in the forced swim test (FST), a commonly used measure of depressive behavior, had lower hippocampal expression of orexin-A. Furthermore, the i.c.v. administration of orexin-A led to a significant reduction in animal immobility in the FST and an increase in the number of cells in the dentate gyrus (Ito et al., 2008). Ito et al. (2008) suggested that the enhancement of cell proliferation in the dentate gyrus by orexin-A might have an antidepressive-like effect. Furthermore, the treatment with the OXR1 antagonist SB-334867 blocked both the orexinA-induced decrease in the FST immobility and the increase in the number of cells in the dentate gyrus. In humans, Brundin et al. (2007a) showed that suicidal patients with major depression exhibit significantly lower orexin-A levels in the cerebrospinal fluid. In addition, low levels of orexin-A in the cerebrospinal fluid are related to pronounced symptoms of inertia and lassitude in suicide attempters (Brundin et al., 2007b).
Experimental evidence suggests the BDNF may have antidepressant-like effects. Shirayama et al. (2002) showed that the infusion of BDNF into the rat hippocampus decreased immobility in the FST. Furthermore, Karege et al. (2005) found that suicidal patients with depression had reduced BDNF levels in their hippocampus. An important question is whether the orexin and BDNF mechanisms interact. To our knowledge, this issue has been addressed only by Yamada et al. (2009) who applied orexin-A and orexin-B to cortical neuron cultures. They found that orexin- $\mathrm{B}$, but not orexin- $\mathrm{A}$, increased the mRNA expression of BDNF.

Taken together, the experimental observations we reported support the view that the orexin-A, as well as the BDNF, might contribute to the beneficial effects of exercise on mood regulation (see Figure 1).

\section{CONCLUSIONS}

In this brief review, we have reported studies that support the view that physical exercise is an effective tool for enhancing cognitive performance and regulating mood. Exercise would induce morphological and functional changes of brain regions that play central roles in successful everyday functioning, such as frontal and temporal cortices, and the hippocampus located in the inner (medial) region of the temporal lobe. The frontal lobe is critical for executive functions (Chieffi et al., 2004, 2009; Iavarone et al., 2007), the temporal lobe for long-term memory skills (Jeneson and Squire, 2011; Lech and Suchan, 2013). The study of exercise-induced hippocampal changes has particularly attracted the interest of many research groups as the hippocampus, along with the olfactory bulb, is the place in the adult in which mammalian brain continues to generate new neurons throughout life (Whitman and Greer, 2009; Kempermann et al., 2015). Thus, it is very important to define accurately the factors that support neurogenesis and are enhanced by exercise. The factors most likely involved in exercise-induced hippocampal changes are the microcirculation and the production of growth factors. Another putative factor that might contribute to the beneficial effects of exercise is the orexin-A. In favor of this hypothesis, as previously reported, there are the following observations: (1) orexinergic neurons have connections to regions involved in cognition and mood regulation such as the hippocampus; (2) orexin-A enhances hippocampal neurogenesis and functions; (3) orexin-A levels increase with exercise. However, currently several important questions remain unanswered: Is the orexinA necessary for hippocampal neurogenesis? Does the systemic administration of orexin-A mimic exercise-induced effects related to neurogenesis, hippocampal structure and function? Does the orexin-A mechanism relate to other mechanisms? E.g., as suggested by an anonymous reviewer, does the administration of an orexin-A antagonist also inhibit exercise-induced increases in BDNF? Future experiments are needed to answer these questions.

Interestingly, regions that benefit from exercise are also those same regions that deteriorate with aging, loading to a decline in a broad array of cognitive processes. Several studies 


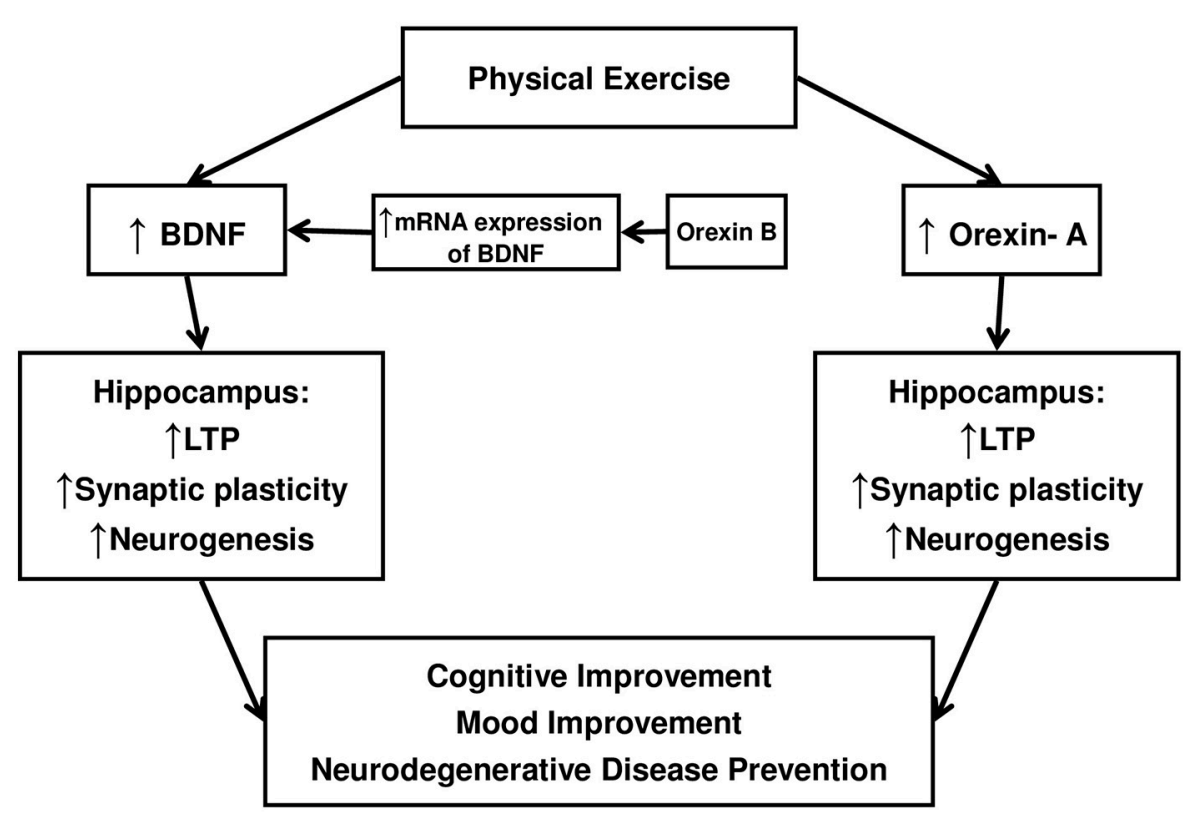

FIGURE 1 | A Schematic diagram to illustrate as Orexin-A and BDNF might contribute to cognitive and mood improvements induced by exercise.

found that exercise is an effective tool in slowing cognitive decline (Erickson et al., 2011; Chapman et al., 2013) and in emotional regulation (Blake et al., 2009; Mura et al., 2014; Kvam et al., 2016). Given the projected increase in the number of adults surviving to advanced age, and the staggering costs of caring for older individuals who suffer from neurological decline and mood disorders, physical activity may represent a simple, but effective and low cost, therapeutic intervention to improve neurocognitive and emotional functions. Furthermore, physical activity is accessible to most adults and is not plagued

\section{REFERENCES}

Akbari, E., Motamedi, F., Davoodi, F. G., Noorbakhshnia, M., and Ghanbarian, E. (2011). Orexin-1 receptor mediates long-term potentiation in the dentate gyrus area of freely moving rats. Behav. Brain Res. 216, 375-380. doi: 10.1016/j.bbr.2010.08.017

Akbari, E., Motamedi, F., Naghdi, N., and Noorbakhshnia, M. (2008). The effect of antagonization of orexin 1 receptors in CA 1 and dentate gyrus regions on memory processing in passive avoidance task. Behav. Brain Res. 187, 172-177. doi: 10.1016/j.bbr.2007.09.019

Akbari, E., Naghdi, N., and Motamedi, F. (2007). The selective orexin 1 receptor antagonist SB-334867-A impairs acquisition and consolidation but not retrieval of spatial memory in Morris water maze. Peptides 28, 650-656. doi: 10.1016/j.peptides.2006.11.002

Allard, J. S., Tizabi, Y., Shaffery, J. P., Trouth, C. O., and Manaye, K. (2004). Stereological analysis of the hypothalamic hypocretin/orexin neurons in an animal model of depression. Neuropeptides 38, 311-315. doi: 10.1016/j.npep.2004.06.004

Arendt, D. H., Ronan, P. J., Oliver, K. D., Callahan, L. B., Summers, T. R., and Summers, C. H. (2013). Depressive behavior and activation of the orexin/hypocretin system. Behav. Neurosci. 127, 86-94. doi: 10.1037/a0031442 by intolerable side effects often found with pharmaceutical treatments.

\section{AUTHOR CONTRIBUTIONS}

SC, GM, MC, and AV carried out the study; IV, AM, ME, VM, AV, FM, and TE participated in the design of the study; SC, GM, $\mathrm{AVi}, \mathrm{GC}$, and MM participated in its design and coordination and helped to draft the manuscript. All authors read and approved the final manuscript.

Barnes, D. E., Yaffe, K., Satariano, W. A., and Tager, I. B. (2003). A longitudinal study of cardiorespiratory fitness and cognitive function in healthy older adults. J. Am. Geriatr. Soc. 51, 459-465. doi: 10.1046/j.1532-5415.2003.51153.x

Blake, H., Mo, P., Malik, S., and Thomas, S. (2009). How effective are physical activity interventions for alleviating depressives ymptoms in older people? A systematic review. Clin. Rehabil. 23, 873-887. doi: 10.1177/0269215509337449

Boscia, F., Passaro, C., Gigantino, V., Perdona, S., Franco, R., Portella, G., et al. (2015). High levels of GPR30 protein in human testicular carcinoma in situ and seminomas correlate with low levels of estrogen receptor-beta and indicate a switch in estrogen responsiveness. J. Cell. Physiol. 230, 1290-1297. doi: $10.1002 /$ jcp. 24864

Bridle, C., Spanjers, K., Patel, S., Atherton, N. M., and Lamb, S. E. (2012). Effect of exercise on depression severity in older people: systematic review and meta-analysis of randomised controlled trials. Br. J. Psychiatry 201, 180-185. doi: 10.1192/bjp.bp.111.095174

Brown, J., Cooper-Kuhn, C. M., Kempermann, G., Van Praag, H., Winkler, J., Gage, F. H., et al. (2003). Enriched environment and physical activity stimulate hippocampal but not olfactory bulb neurogenesis. Eur. J. Neurosci. 17, 2042-2046. doi: 10.1046/j.1460-9568.2003.02647.x

Brundin, L., Björkqvist, M., Petersén, Å., and Träskman-Bendz, L. (2007a). Reduced orexin levels in the cerebrospinal fluid of suicidal patients 
with major depressive disorder. Eur. Neuropsychopharm. 17, 573-579. doi: 10.1016/j.euroneuro.2007.01.005

Brundin, L., Petersén, Å., Björkqvist, M., and Träskman-Bendz, L. (2007b). Orexin and psychiatric symptoms in suicide attempters. J. Affect. Disord. 100, 259-263. doi: 10.1016/j.jad.2006.10.019

Chapman, S. B., Aslan, S., Spence, J. S., Defina, L. F., Keebler, M. W., Didehbani, N., et al. (2013). Shorter term aerobic exercise improves brain, cognition, and cardiovascular fitness in aging. Front. Aging Neurosci. 5:75. doi: 10.3389/fnagi.2013.00075

Chieffi, S. (2016a). Visual illusion and line bisection: a bias hypothesis revisited. Exp. Brain Res. 234, 1451-1458. doi: 10.1007/s00221-015-4550-z

Chieffi, S. (2016b). Orexinergic system dysregulation in depression. J. Psychiatry 20:e107. doi: 10.4172/2378-5756.1000e107

Chieffi, S., Conson, M., and Carlomagno, S. (2004). Movement velocity effects on kinaesthetic localisation of spatial positions. Exp. Brain Res. 158, 421-426. doi: 10.1007/s00221-004-1916-Z

Chieffi, S., Iachini, T., Iavarone, A., Messina, G., Viggiano, A., and Monda, M. (2014a). Flanker interference effects in a line bisection task. Exp. Brain Res. 232, 1327-1334. doi: 10.1007/s00221-014-3851-y

Chieffi, S., Iavarone, A., and Carlomagno, S. (2008). Effects of spatiotopic factors on bisection of radial lines. Exp. Brain Res. 189, 129-132. doi: 10.1007/s00221-008-1458-x

Chieffi, S., Iavarone, A., Iaccarino, L., La Marra, M., Messina, G., De Luca, V., et al. (2014b). Age-related differences in distractor interference on line bisection. Exp. Brain Res. 232, 3659-3664. doi: 10.1007/s00221-014-4056-0

Chieffi, S., Iavarone, A., La Marra, M., Messina, G., Dalia, C., et al. (2015). Vulnerability to distraction in Schizophrenia. J. Psychiatry 18:228. doi: 10.4172/2378-5756.1000228

Chieffi, S., Iavarone, A., Viggiano, A., Monda, M., and Carlomagno, S. (2012). Effect of a visual distractor on line bisection. Exp. Brain Res. 219, 489-498. doi: 10.1007/s00221-012-3106-8

Chieffi, S., Secchi, C., and Gentilucci, M. (2009). Deictic word and gesture production: their interaction. Behav. Brain Res. 203, 200-206. doi: 10.1016/j.bbr.2009.05.003

Clark, P. J., Brzezinska, W. J., Thomas, M. W., Ryzhenko, N. A., Toshkov, S. A., and Rhodes, J. S. (2008). Intact neurogenesis is required for benefits of exercise on spatial memory but not motor performance or contextual fear conditioning in C57BL/6J mice. Neuroscience 155, 1048-1058. doi: 10.1016/j.neuroscience.2008.06.051

Colcombe, S. J., Erickson, K. I., Scalf, P. E., Kim, J. S., Prakash, R., McAuley, E., et al. (2006). Aerobic exercise training increases brain volume in aging humans. J. Gerontol. A Biol. Sci. Med. Sci. 61, 1166-1170. doi: 10.1093/gerona/61.11.1166

Colcombe, S., and Kramer, A. F. (2003). Fitness effects on the cognitive function of older adults a meta-analytic study. Psychol. Sci. 14, 125-130. doi: 10.1111/1467-9280.t01-1-01430

Cotman, C. W., and Berchtold, N. C. (2002). Exercise: a behavioral intervention to enhance brain health and plasticity. Trends Neurosci. 25, 295-301. doi: 10.1016/S0166-2236(02)02143-4

Cotman, C. W., Berchtold, N. C., and Christie, L. A. (2007). Exercise builds brain health: key roles of growth factor cascades and inflammation, Trends Neurosci. 30, 464-472. doi: 10.1016/j.tins.2007.06.011

Date, Y., Ueta, Y., Yamashita, H., Yamaguchi, H., Matsukura, S., Kangawa, K., et al. (1999). Orexins, orexigenic hypothalamic peptides, interact with autonomic, neuroendocrine and neuroregulatory systems. Proc. Natl. Acad. Sci. U.S.A. 96, 748-753. doi: 10.1073/pnas.96.2.748

Erickson, K. I., Voss, M. W., Prakash, R. S., Basak, C., Szabo, A., Chaddock, L., et al. (2011). Exercise training increases size of hippocampus and improves memory. Proc. Natl. Acad. Sci. U.S.A. 108, 3017-3022. doi: 10.1073/pnas.1015950108

Eriksson, P. S., Perfilieva, E., Björk-Eriksson, T., Alborn, A. M., Nordborg, C., Peterson, D. A., et al. (1998). Neurogenesis in the adult human hippocampus. Nat. Med. 4, 1313-1317. doi: 10.1038/3305

Ferris, L. T., Williams, J. S., and Shen, C. L. (2007). The effect of acute exercise on serum brain-derived neurotrophic factor levels and cognitive function. Med. Sci. Sport Exer. 39, 728-734. doi: 10.1249/mss.0b013e31802f04c7

Franco, R., Zappavigna, S., Gigantino, V., Luce, A., Cantile, M., Cerrone, M., et al. (2014). Urotensin II receptor determines prognosis of bladder cancer regulating cell motility/invasion. J. Exp. Clin. Cancer Res. 33:48. doi: 10.1186/1756-9966-33-48
Gage, F. H. (2000). Mammalian neural stem cells. Science 287, 1433-1438. doi: $10.1126 /$ science.287.5457.1433

Galeone, F., Pappalardo, S., Chieffi, S., Iavarone, A., and Carlomagno, S. (2011). Anosognosia for memory deficit in amnestic mild cognitive impairment and Alzheimer's disease. Int. J. Geriatr. Psychiatry. 26, 695-701. doi: $10.1002 /$ gps.2583

Godefroy, O., Jeannerod, M., Allain, P., and Le Gall, D. (2008). Frontal lobe, executive functions and cognitive control. Rev. Neurol. 164(Suppl. 3), S119S127. doi: 10.1016/S0035-3787(08)73302-2

Gotter, A. L., Roecker, A. J., Hargreaves, R., Coleman, P. J., Winrow, C. J., and Renger, J. J. (2012). Orexin receptors as therapeutic drug targets. Prog. Brain Res. 198, 163-188. doi: 10.1016/B978-0-444-59489-1.00010-0

Grego, F., Vallier, J. M., Collardeau, M., Rousseu, C., Cremieux, J., and Brisswalter, J. (2005). Influence of exercise duration and hydration status on cognitive function during prolonged cycling exercise. Int. J. Sports Med. 26, 27-33. doi: 10.1055/s-2004-817915

Griffin, É. W., Mullally, S., Foley, C., Warmington, S. A., O’Mara, S. M., and Kelly, A. M. (2011). Aerobic exercise improves hippocampal function and increases BDNF in the serum of young adult males. Physiol. Behav. 104, 934-941. doi: 10.1016/j.physbeh.2011.06.005

Hara, J., Beuckmann, C. T., Nambu, T., Willie, J. T., Chemelli, R. M., Sinton, C. M., et al. (2001). Genetic ablation of orexin neurons in mice results in narcolepsy, hypophagia, and obesity. Neuron 30, 345-354. doi: 10.1016/S0896-6273(01)00293-8

Heine, V. M., Maslam, S., Joëls, M., and Lucassen, P. J. (2004). Prominent decline of newborn cell proliferation, differentiation, and apoptosis in the aging dentate gyrus, in absence of an age-related hypothalamus-pituitary-adrenal axis activation. Neurobiol. Aging 25, 361-375. doi: 10.1016/S0197-4580(03) 00090-3

Iavarone, A., Patruno, M., Galeone, F., Chieffi, S., and Carlomagno, S. (2007). Brief report: error pattern in an autistic savant calendar calculator. J. Autism. Dev. Disord. 37, 775-779. doi: 10.1007/s10803-006-0190-2

Ito, N., Yabe, T., Gamo, Y., Nagai, T., Oikawa, T., Yamada, H., et al. (2008). Icv administration of orexin-A induces an antidepressive-like effect through hippocampal cell proliferation. Neuroscience 157, 720-732. doi: 10.1016/j.neuroscience.2008.09.042

Jack, C. R., Wiste, H. J., Vemuri, P., Weigand, S. D., Senjem, M. L., Zeng, G., et al. (2010). Brain beta-amyloid measures and magnetic resonance imaging atrophy both predict time-to-progression from mild cognitive impairment to Alzheimer's disease. Brain 133, 3336-3348. doi: 10.1093/brain/awq277

Jeneson, A., and Squire, L. R. (2011). Working memory, long-term memory, and medial temporal lobe function. Learn. Mem. 19, 15-25. doi: 10.1101/lm.024018.111

Ji, J. F., Ji, S. J., Sun, R., Li, K., Zhang, Y., Zhang, L. Y., et al. (2014). Forced running exercise attenuates hippocampal neurogenesis impairment and the neurocognitive deficits induced by whole-brain irradiation via the BDNF-mediated pathway. Biochem. Biophys. Res. Commun. 443, 646-651. doi: 10.1016/j.bbrc.2013.12.031

Karege, F., Vaudan, G., Schwald, M., Perroud, N., and La Harpe, R. (2005). Neurotrophin levels in postmortem brains of suicide victims and the effects of antemortem diagnosis and psychotropic drugs. Brain Res. Mol. Brain Res. 136, 29-37. doi: 10.1016/j.molbrainres.2004.12.020

Kastin, A. J., and Akerstrom, V. (1999). Orexin A but not orexin B rapidly enters brain from blood by simple diffusion. J. Pharmacol. Exp. Ther. 289, 219-223.

Kempermann, G., Brandon, E. P., and Gage, F. H. (1998). Environmental stimulation of $129 / \mathrm{SvJ}$ mice causes increased cell proliferation and neurogenesis in the adult dentate gyrus. Curr. Biol. 8, 939-942. doi: 10.1016/S0960-9822(07)00377-6

Kempermann, G., Jessberger, S., Steiner, B., and Kronenberg, G. (2004). Milestones of neuronal development in the adult hippocampus. Trends Neurosci. 27, 447-452. doi: 10.1016/j.tins.2004.05.013

Kempermann, G., Kuhn, H. G., and Gage, F. H. (1997). More hippocampal neurons in adult mice living in an enriched environment. Nature 386, 493-495. doi: $10.1038 / 386493 \mathrm{a} 0$

Kempermann, G., Song, H., and Gage, F. H. (2015). Neurogenesis in the adult hippocampus. Cold Spring Harb. Perspect. Biol. 7:a018812. doi: $10.1101 /$ cshperspect.a018812 
Kirwan, C. B., and Stark, C. E. (2004). Medial temporal lobe activation during encoding and retrieval of novel face-name pairs. Hippocampus 14, 919-930. doi: 10.1002/hipo. 20014

Kiyashchenko, L. I., Mileykovskiy, B. Y., Maidment, N., Lam, H. A., Wu, M. F., John, J., et al. (2002). Release of hypocretin (orexin) during waking and sleep states. J. Neurosci. 22, 5282-5286.

Kogan, J. H., Frankland, P. W., and Silva, A. J. (2000). Long-term memory underlying hippocampus-dependent social recognition in mice. Hippocampus 10, 47-56. doi: 10.1002/(SICI)1098-1063(2000)10:1<47::AID-HIPO5>3. $0 . \mathrm{CO} ; 2-6$

Kramer, A. F., Hahn, S., Cohen, N. J., Banich, M. T., McAuley, E., Harrison, C. R., et al. (1999). Ageing, fitness and neurocognitive function. Nature 400, 418-419. doi: $10.1038 / 22682$

Krogh, J., Rostrup, E., Thomsen, C., Elfving, B., Videbech, P., and Nordentoft, M. (2014). The effect of exercise on hippocampal volume and neurotrophines in patients with major depression-a randomized clinical trial. J. Affect. Disord. 165, 24-30. doi: 10.1016/j.jad.2014.04.041

Kuhn, H. G., Dickinson-Anson, H., and Gage, F. H. (1996). Neurogenesis in the dentate gyrus of the adult rat: age-related decrease of neuronal progenitor proliferation. J. Neurosci. 16, 2027-2033.

Kvam, S., Kleppe, C. L., Nordhus, I. H., and Hovland, A. (2016). Exercise as a treatment for depression: a meta-analysis. J. Affect. Disord. 202, 67-86. doi: 10.1016/j.jad.2016.03.063

Larson, E. B., Wang, L., Bowen, J. D., McCormick, W. C., Teri, L., Crane, P., et al. (2006). Exercise is associated with reduced risk for incident dementia among persons 65 years of age and older. Ann. Intern. Med. 144, 73-81. doi: 10.7326/0003-4819-144-2-200601170-00004

Lech, R. K., and Suchan, B. (2013). The medial temporal lobe: memory and beyond. Behav. Brain Res. 254, 45-49. doi: 10.1016/j.bbr.2013.06.009

Leung, H. C., Skudlarski, P., Gatenby, J. C., Peterson, B. S., and Gore, J. C. (2000). An event-related functional MRI study of the Stroop color word interference task. Cereb. Cortex 10, 552-560. doi: 10.1093/cercor/10.6.552

Marcus, J. N., Aschkenasi, C. J., Lee, C. E., Chemelli, R. M., Saper, C. B., Yanagisawa, M., et al. (2001). Differential expression of orexin receptors 1 and 2 in the rat brain. J. Comp. Neurol. 435, 6-25. doi: 10.1002/cne.1190

Marra, L., Cantile, M., Scognamiglio, G., Perdonà, S., La Mantia, E., Cerrone, M., et al. (2013). Deregulation of HOX B13 expression in urinary bladder cancer progression. Curr. Med. Chem. 20, 833-839. doi: 10.2174/0929867311320060008

Martins, P. J., D’Almeida, V., Pedrazzoli, M., Lin, L., Mignot, E., and Tufik, S. (2004). Increased hypocretin-1 (orexin-a) levels in cerebrospinal fluid of rats after short-term forced activity. Regul. Pept. 117, 155-158. doi: 10.1016/j.regpep.2003.10.003

Messina, A., De Fusco, C., Monda, V., Esposito, M., Moscatelli, F., Valenzano, A., et al. (2016). Role of the orexin system on the Hypothalamus-Pituitary-Thyroid Axis. Front. Neural Circuits 25, 10:66. doi: 10.3389/fncir.2016.00066

Messina, G., De Luca, V., Viggiano, A., Ascione, A., Iannaccone, T., Chieffi, S., et al. (2013). Autonomic nervous system in the control of energy balance and body weight: personal contributions. Neurol. Res. Int. 2013:639280. doi: 10.1155/2013/639280

Messina, G., Di Bernardo, G., Messina, A., Dalia, C., and Chieffi, S. (2014a). Brief exercise enhances blood hypocretin-1 in sedentary men. J. Sports Med. Doping Stud. 4:149. doi: 10.4172/2161-0673.1000149

Messina, G., Di Bernardo, G., Viggiano, A., De Luca, V., Monda, V., Messina, A., et al. (2016). Exercise increases the level of plasma orexin A in humans. J. Basic Clin. Physiol. Pharmacol. 27, 611-616. doi: 10.1515/jbcpp-2015-0133

Messina, G., Monda, V., Moscatelli, F., Valenzano, A. A., Monda, G., et al. (2015a). Role of Orexin system in obesity. Biol. Med. 7:248. doi: 10.4172/0974-8369.1000248

Messina, G., Palmieri, F., Monda, V., Messina, A., Dalia, C., et al. (2015b). Exercise causes muscle GLUT4 Translocation in an insulin-independent manner. Biol. Med. 1:007. doi: 10.4172/0974-8369.1000\$3007

Messina, G., Viggiano, A., Tafuri, D., Palmieri, F., De Blasio, S., et al. (2014b). Role of orexin in obese patients in the intensive care unit. J. Anesth. Clin. Res. 5:395. doi: 10.4172/2155-6148.1000395

Mura, G., Moro, M. F., Patten, S. B., and Carta, M. G. (2014). Exercise as an addon strategy for the treatment of major depressive disorder: a systematic review. CNS Spectr. 19, 1-13. doi: 10.1017/S1092852913000953
Nakabayashi, M., Suzuki, T., Takahashi, K., Totsune, K., Muramatsu, Y., Kaneko, C., et al. (2003). Orexin-A expression in human peripheral tissues. Mol. Cell. Endocrinol. 205, 43-50. doi: 10.1016/S0303-7207(03)00206-5

Nattie, E., and Li, A. (2012). Respiration and autonomic regulation and orexin. Prog. Brain Res. 198, 25-46. doi: 10.1016/B978-0-444-59489-1.00004-5

Neeper, S. A., Gomezpinilla, F., Choi, J., and Cotman, C. (1995). Exercise and brain neurotrophins. Nature 373, 109-109. doi: 10.1038/373109a0

Nomoto, M., Takeda, Y., Uchida, S., Mitsuda, K., Enomoto, H., Saito, K., et al. (2012). Dysfunction of the RAR/RXR signaling pathway in the forebrain impairs hippocampal memory and synaptic plasticity. Mol. Brain. 5:8. doi: 10.1186/1756-6606-5-8

Palotai, M., Telegdy, G., Ekwerike, A., and Jászberényi, M. (2014). The action of orexin B on passive avoidance learning. Involvement of neurotransmitters. Behav. Brain Res. 272, 1-7. doi: 10.1016/j.bbr.2014.06.016

Pereira, A. C., Huddleston, D. E., Brickman, A. M., Sosunov, A. A., Hen, R., McKhann, G. M., et al. (2007). An in vivo correlate of exercise-induced neurogenesis in the adult dentate gyrus. Proc. Natl. Acad. Sci. U.S.A. 104, 5638-5643. doi: 10.1073/pnas.0611721104

Podewils, L. J., Guallar, E., Kuller, L. H., Fried, L. P., Lopez, O. L., Carlson, M., et al. (2005). Physical activity, APOE genotype, and dementia risk: findings from the cardiovascular health cognition study. Am. J. Epidemiol. 161, 639-651. doi: 10.1093/aje/kwi092

Raz, N., Lindenberger, U., Rodrigue, K. M., Kennedy, K. M., Head, D., Williamson, A., et al. (2005). Regional brain changes in aging healthy adults: general trends, individual differences and modifiers. Cereb. Cortex 15, 1676-1689. doi: 10.1093/cercor/bhi044

Rejdak, K., Papuć, E., Grieb, P., and Stelmasiak, Z. (2009). Decreased cerebrospinal fluid hypocretin-1 (orexin A) in patients after repetitive generalized tonicclonic seizures. Epilepsia 50, 1641-1644. doi: 10.1111/j.1528-1167.2008.01990.x

Roca, M., Parr, A., Thompson, R., Woolgar, A., Torralva, T., Antoun, N., et al. (2010). Executive function and fluid intelligence after frontal lobe lesions. Brain 133, 234-247. doi: 10.1093/brain/awp269

Rosano, C., Venkatraman, V. K., Guralnik, J., Newman, A. B., Glynn, N. W., Launer, L., et al. (2010). Psychomotor speed and functional brain MRI 2 years after completing a physical activity treatment. J. Gerontol. A Biol. Sci. Med. Sci. 65, 639-647. doi: 10.1093/gerona/glq038

Sakurai, T., Amemiya, A., Ishii, M., Matsuzaki, I., Chemelli, R. M., Tanaka, H., et al. (1998). Orexins and orexin receptors: a family of hypothalamic neuropeptides and $\mathrm{G}$ protein-coupled receptors that regulate feeding behavior. Cell 92, 573-585. doi: 10.1016/S0092-8674(00)80949-6

Sakurai, T., and Mieda, M. (2011). Connectomics of orexin-producing neurons: interface of systems of emotion, energy homeostasis and arousal. Trends Pharmacol. Sci. 32, 451-462. doi: 10.1016/j.tips.2011.03.007

Saper, C. B., Scammell, T. E., and Lu, J. (2005). Hypothalamic regulation of sleep and circadian rhythms. Nature 437, 1257-1263. doi: 10.1038/nature04284

Scammell, T. E., and Winrow, C. J. (2011). Orexin receptors: pharmacology and therapeutic opportunities. Annu. Rev. Pharmacol. 51, 243-266. doi: 10.1146/annurev-pharmtox-010510-100528

Sheline, Y. I. (2003). Neuroimaging studies of mood disorder effects on the brain. Biol. Psychiatry 54, 338-352. doi: 10.1016/S0006-3223(03)00347-0

Shirayama, Y., and Chaki, S. (2006). Neurochemistry of the nucleus accumbens and its relevance to depression and antidepressant action in rodents. Curr. Neuropharm. 4, 277-291. doi: 10.2174/157015906778520773

Shirayama, Y., Chen, A. C., Nakagawa, S., Russell, D. S., and Duman, R. S. (2002) Brain-derived neurotrophic factor produces antidepressant effects in behavioral models of depression. J. Neurosci. 22, 3251-3261.

Spalding, K. L., Bergmann, O., Alkass, K., Bernard, S., and Salehpour, M., Huttner, H. B., et al. (2013). Dynamics of hippocampal neurogenesis in adult humans. Cell 153, 1219-1227. doi: 10.1016/j.cell.2013.05.002

Steffens, D. C., Byrum, C. E., McQuoid, D. R., Greenberg, D. L., Payne, M. E., and Blitchington, T. F. (2000). Hippocampal volume in geriatric depression. Biol. Psychiatry 48, 301-309. doi: 10.1016/S0006-3223(00)00829-5

Taheri, S., Gardiner, J., Hafizi, S., Murphy, K., Dakin, C., Seal, L., et al. (2001). Orexin A immunoreactivity and preproorexin mRNA in the brain of Zucker and WKY rats. Neuroreport 12, 459-464. doi: 10.1097/00001756-200103050-00008

Thompson, J. L., and Borgland, S. L. (2011). A role for hypocretin/orexin in motivation. Behav. Brain Res. 217, 446-453. doi: 10.1016/j.bbr.2010.09.028 
Trivedi, P., Yu, H., MacNeil, D. J., Van der Ploeg, L. H., and Guan, X. M. (1998). Distribution of orexin receptor mRNA in the rat brain. FEBS Lett. 438, 71-75. doi: 10.1016/S0014-5793(98)01266-6

Tsunematsu, T., and Yamanaka, A. (2012). The role of orexin/hypocretin in the central nervous system and peripheral tissues. Vitam. Horm. 89, 19-33. doi: 10.1016/B978-0-12-394623-2.00002-0

van Praag, H., Christie, B. R., Sejnowski, T. J., and Gage, F. H. (1999a). Running enhances neurogenesis, learning, and long-term potentiation in mice. Proc Natl. Acad. Sci. U.S.A. 96, 13427-13431. doi: 10.1073/pnas.96.23.13427

van Praag, H., Kempermann, G., and Gage, F. H. (1999b). Running increases cell proliferation and neurogenesis in the adult mouse dentate gyrus. Nat. Neurosci. 2, 266-270. doi: 10.1038/6368

van Praag, H., Shubert, T., Zhao, C., and Gage, F. H. (2005). Exercise enhances learning and hippocampal neurogenesis in aged mice. J. Neurosci. 25, 8680-8685. doi: 10.1523/JNEUROSCI.1731-05.2005

Vaynman, S., Ying, Z., and Gomez-Pinilla, F. (2004). Hippocampal BDNF mediates the efficacy of exercise on synaptic plasticity and cognition. Eur. J. Neurosci. 20, 2580-2590. doi: 10.1111/j.1460-9568.2004.03720.x

Wayner, M. J., Armstrong, D. L., Phelix, C. F., and Oomura, Y. (2004). Orexin-A (Hypocretin-1) and leptin enhance LTP in the dentate gyrus of rats in vivo. Peptides 25, 991-996. doi: 10.1016/j.peptides.2004. 03.018

Whitman, M. C., and Greer, C. A. (2009). Adult neurogenesis and the olfactory system. Prog. Neurobiol. 89, 162-175. doi: 10.1016/j.pneurobio.2009.07.003

Winter, B., Breitenstein, C., Mooren, F. C., Voelker, K., Fobker, M., Lechtermann, A., et al. (2007). High impact running improves learning. Neurobiol. Learn. Mem. 87, 597-609. doi: 10.1016/j.nlm.2006.11.003

Wu, M. F., John, J., Maidment, N., Lam, H. A., and Siegel, J. M. (2002). Hypocretin release in normal and narcoleptic dogs after food and sleep deprivation, eating, and movement. Am. J. Physiol. Regul. Integr. Comp. Physiol. 283, R1079-R1086. doi: 10.1152/ajpregu.00207.2002

Yaffe, K., Barnes, D., Nevitt, M., Lui, L. Y., and Covinsky, K. (2001). A prospective study of physical activity and cognitive decline in elderly women: women who walk. Arch. Intern. Med. 161, 1703-1708. doi: 10.1001/archinte.161. 14.1703

Yamada, N., Katsuura, G., Tatsuno, I., Kawahara, S., Ebihara, K., Saito, Y., et al. (2009). Orexins increase mRNA expressions of neurotrophin3 in rat primary cortical neuron cultures. Neurosci. Lett. 450, 132-135. doi: 10.1016/j.neulet.2008.11.028

Yang, L., Zou, B., Xiong, X., Pascual, C., and Xie, J., Malik, A., et al. (2013). Hypocretin/orexin neurons contribute to hippocampus-dependent social memory and synaptic plasticity in mice. J. Neurosci. 33, 5275-5284 doi: 10.1523/JNEUROSCI.3200-12.2013

Yoshida, K., McCormack, S., Espana, R. A., Crocker, A., and Scammell, T. E. (2006). Afferents to the orexin neurons of the rat brain. J. Comp. Neurol. 494, 845-861. doi: 10.1002/cne.20859

Zeineh, M. M., Engel, S. A., Thompson, P. M., and Bookheimer, S. Y. (2003). Dynamics of the hippocampus during encoding and retrieval of face-name pairs. Science 299, 577-580. doi: 10.1126/science.1077775

Zhao, X., Zhang, R. X., Tang, S., Ren, Y. Y., Yang, W. X., Liu, X. M., et al. (2014). Orexin-A-induced ERK $1 / 2$ activation reverses impaired spatial learning and memory in pentylenetetrazol-kindled rats via OX1R-mediated hippocampal neurogenesis. Peptides 54, 140-147. doi: 10.1016/j.peptides.2013.11.019

Conflict of Interest Statement: The authors declare that the research was conducted in the absence of any commercial or financial relationships that could be construed as a potential conflict of interest.

Copyright (C) 2017 Chieffi, Messina, Villano, Messina, Esposito, Monda, Valenzano, Moscatelli, Esposito, Carotenuto, Viggiano, Cibelli and Monda. This is an openaccess article distributed under the terms of the Creative Commons Attribution License (CC BY). The use, distribution or reproduction in other forums is permitted, provided the original author(s) or licensor are credited and that the original publication in this journal is cited, in accordance with accepted academic practice. No use, distribution or reproduction is permitted which does not comply with these terms. 